\title{
A LEI DE CUNHAGEM DE 4 DE AGOSTO DE 1688 E A EMISSÃO DE MOEDA PROVINCIAL NO BRASIL (1695-1702) UM EPISÓDIO DA HISTÓRIA MONETÁRIA DO BRASIL *
}

\section{Fernando Carlos Greenhalgh de Cerqueira Lima ${ }^{* *}$}

\begin{abstract}
RESUMO O objetivo central deste trabalho é examinar os motivos que levaram à cunhagem de moeda provincial no Brasil a partir da instalação, entre 1695 e 1702, de uma casa da moeda "itinerante" com esse exclusivo propósito. A seção 1 do trabalho analisa as principais características da circulação monetária no Brasil na segunda metade do século XVII. A seguir são descritos os impactos da Lei de Cunhagem de 4 de agosto de 1688, incluindo os chamados "motins da moeda". Na seção 3 comenta-se a visão das autoridades coloniais sobre as causas e conseqüências da falta de moeda, assim como suas propostas para solucionar o problema. Segue-se uma breve análise das atividades da Casa da Moeda nas cidades em que operou. A última seção resume os argumentos apresentados ao longo do trabalho.
\end{abstract}

Palavras-chave: moeda; história econômica; Brasil colonial

Código JEL: N16

\section{THE MiNT LAW OF AUgUSt $4^{\text {th }}, 1688$ AND the COINAge \\ OF PROVINCIAL CURRENCY IN BRAZIL (1695-1702):}

A MONEY HISTORY EPISODE IN BRAZIL

ABSTRACT The main objective of this paper is to examine the reasons that led to the coinage of provincial currency in Brazil by local mints, between 1695 and 1702 . Section 1 analyses the main features of the monetary circulation in Brazil during the second half of the seventeenth century. Section 2 describes the impacts of the

* Artigo recebido em 10 de novembro de 2003 e aprovado em 22 de junho de 2005. O autor agradece as sugestões das professoras Elisa Muller e Vânia Cury a uma versão preliminar deste trabalho, assim como as contribuições de dois pareceristas anônimos. As opiniões e os erros remanescentes são de responsabilidade única do autor.

** Professor do Instituto de Economia da UFRJ, e-mail: fcgclima@terra.com.br 
Mint Law of 1688, including the so-called "money riots". Section 3 comments on the causes and consequences of the monetary scarcity as perceived by the colonial authorities in the early 1690's, as well as their proposals to overcome this problem. Section 4 presents a brief analysis of the workings of the mints. The final section summarizes the main arguments developed in the paper.

Key words: money; economic history; colonial Brazil JEL Code N16 


\section{INTRODUÇÃO}

Ao longo da segunda metade do século XVII, os problemas decorrentes da falta de moeda metálica no Brasil foram sentidos de maneira crescente. A percepção geral, tanto na metrópole como na colônia, era de que a escassez de numerário prejudicava a atividade econômica e, portanto, contribuía para reduzir a arrecadação de impostos. A colônia convivia também com outros problemas relacionados à moeda metálica, tais como as manipulações monetárias realizadas a partir da década de 1640 em Portugal, e as práticas de cerceio e falsificação de moeda. A Lei de Cunhagem de 4 de agosto de 1688, que determinou não só um "levantamento" geral da moeda, mas também que esta corresse a peso, agravou sobremaneira a situação, dando origem aos chamados "motins da moeda".

Em resposta à crescente sensação de escassez de moeda, desde meados do século XVII as autoridades coloniais demandavam da metrópole o estabelecimento de um diferencial entre os valores nominais das moedas correntes no Brasil e em Portugal, ou mesmo a abertura de uma Casa da Moeda para cunhar moeda de circulação restrita à colônia. Em 1694, essas duas demandas foram finalmente atendidas.

Este trabalho examina as razões que acabaram por levar à instalação, na Bahia, no Rio de Janeiro e em Pernambuco, de uma Casa da Moeda com o único propósito de cunhar moeda provincial. Na seção 1, após uma breve digressão sobre a importância da cunhagem de moeda com valor intrínseco, são analisados alguns dos principais problemas relativos à circulação monetária no Brasil a partir de meados do século XVII. A seção 2 descreve os impactos da lei monetária de 4 de agosto de 1688, enfatizando a "redução da moeda a peso". A seção 3 comenta a visão do governador-geral Câmara Coutinho, expressa em cartas endereçadas ao rei no início dos anos 1690, sobre as causas e conseqüências da falta de moeda, assim como suas propostas para solucionar o problema, propostas estas que vieram, em linhas gerais, a ser incorporadas na lei de 1694 que instituiu a Casa da Moeda da Bahia. A seção 4 relata as operações da Casa da Moeda "itinerante", contrastando-as com o que havia sido proposto pelo governador-geral, e analisa alguns de seus resultados. A seção conclusiva resume os argumentos apresentados ao longo do trabalho, procurando mostrar que a cunhagem de moeda 
provincial, além de ter sido motivada por razões fiscais, atendia a interesses tanto dos produtores como dos comerciantes sediados na colônia.

\section{ANTECEDENTES: A CIRCULAÇÃo MONETÁRIA NO BRASIL ANTES DAS MEDIDAS ADOTADAS EM 1688}

\subsection{A necessidade de cunhagem de moeda com valor intrínseco}

Cabe inicialmente tecer algumas breves considerações sobre as razões que levavam os indivíduos, nos idos dos séculos XVI a XVII, a demandar moeda especificamente metálica, em vez de outros tipos de moeda sem valor intrínseco. As moedas de então tinham de ter valor elas mesmas, em parte pelas razões apontadas nos livros-texto: para ser moeda, uma coisa tinha de possuir determinadas qualidades que o ouro e a prata tinham, como divisibilidade, facilidade de transporte - peso e volume em relação ao valor nominal —, ser difícil de falsificar etc. Essas condições cumpridas, poderia a moeda ser um "equivalente geral das trocas" e o seu uso reduzir de fato os custos de transação.

Entretanto, para servir como meio de pagamento, é imperioso também que esse objeto incorpore informação necessária sem custo para obtê-la, ${ }^{1} \mathrm{o}$ que sempre dependeu de avanços tecnológicos. A moeda de papel, ou feita de outro material mais barato que o ouro ou a prata, só pôde ser adotada a partir do momento em que tal tecnologia passou a estar disponível. ${ }^{2}$ Goodhart (1989, p. 34) explica que existem duas maneiras pelas quais as sociedades resolveram o problema de encontrar um meio de pagamento padrão que incorporasse informação suficiente capaz de torná-lo aceito sem necessidade de detalhada verificação física. A primeira é a utilização de objetos de diferentes valores de uso que também simbolizassem algum valor abstrato de estima, geralmente status ou poder. A segunda é quando uma autoridade externa provê a informação no próprio objeto, através de uma estampa ou marca, de maneira que informe aos usuários potenciais sobre as características do objeto.

Classifica-se como cartalista quem defende a idéia de que o uso da moeda (currency) era baseado essencialmente no simbolismo do poder da autoridade emitente, ou seja, que a currency torna-se money porque as coins são cunhadas com a insígnia do rei, e não porque são de ouro, de prata ou de 
cobre. Por outro lado, segundo os metalistas, o valor da currency dependia do seu valor intrínseco, sendo o papel da autoridade restrito ao provimento da informação necessária sobre as características intrínsecas das currencies. ${ }^{3}$

O uso de papel-moeda no lugar das moedas metálicas nos últimos dois séculos oferece forte suporte para a visão cartalista. Mas, como ressalta Goodhart (1989, p. 35), é preciso responder a uma questão crucial, de caráter histórico: se o valor da moeda estava no carimbo que lhe era aplicado pelo soberano, por que utilizar metais preciosos, que são caros, e não um material mais barato? Duas razões podem ser destacadas: a facilidade de falsificação das moedas e o fato de o poder dos reinos ser limitado, tanto em termos absolutos como geograficamente. Portanto, para tornar mais atraente e diminuir os riscos de reter moeda, era necessário que esta tivesse elevado valor intrínseco. As autoridades não podiam obter muitos ganhos de senhoriagem porque não tinham muito poder.

A conversibilidade da moeda era um fator fundamental: as pessoas só aceitariam uma moeda que pudesse ser facilmente convertida em moeda internacional, em uma época em que, na Europa, o comércio era o setor dinâmico. $\mathrm{O}$ fato de moedas estrangeiras circularem abertamente prova isso. Demandavam-se dois tipos de moeda metálica. Em primeiro lugar, e mais importante, demandava-se moeda de ouro e de prata, a única, na época, que poderia ter aceitação internacional. ${ }^{4}$ Era com essas moedas de ouro e de prata que, em última instância, eram pagas as importações e as dívidas. Era também essa a forma de ativo que, em momentos de incerteza, de elevação da preferência pela liquidez - expectativa de desvalorizações futuras, confiscos da Inquisição etc. - melhor servia para entesouramento.

Em segundo lugar, havia demanda por moeda de cobre e moeda de prata de baixo valor extrínseco - e ainda menor valor intrínseco. Essas moedas eram usadas exclusivamente no âmbito doméstico e, no caso de Portugal, o poder liberatório das moedas de cobre era, até o final do século XVII, de apenas 100 réis. ${ }^{5} \mathrm{O}$ custo de produção de moedas de baixo valor extrínseco era relativamente mais alto que o de produção de moedas de elevado valor nominal, já que ambas tinham custo unitário semelhante, incentivando assim a cunhagem de moedas de mais elevado valor (Van Der Wee, 1977; Sargent e Velde, 1997). 
Portugal manteve o regime bimetálico até 1797, quando pela primeira vez emitiu papel-moeda (Souza, 1999). A questão da "política monetária" — ou "política de cunhagem" - esteve, até então, centrada em torno das dificuldades de gerenciamento típicas de tal regime monetário, em particular aquelas relacionadas à Lei de Gresham, somadas ao combate às práticas de falsificação e cerceio de moeda, facilitadas, por sua vez, pelas técnicas ainda rudimentares de cunhagem. A tendência geral, tanto na colônia como na metrópole, era de escassez crônica de moedas de ouro e prata de valor nominal elevado, assim como de moedas de prata e cobre de baixo valor nominal. A moeda de cobre, vale lembrar, era fabricada exclusivamente pelo Estado, em volume pequeno, porque o cobre era muito demandado para usos não monetários - por exemplo, na fabricação de canhões e de navios.

\subsection{Escassez, demanda e oferta de moeda}

Um dos aspectos econômicos mais enfatizados na historiografia do Brasil colonial é a escassa circulação de moeda metálica, não sendo feita distinção entre os diferentes tipos de moeda. A suposição, portanto, era de que a escassez de numerário fosse generalizada. A economia colonial teria sido uma economia não monetária. Tal aspecto justificaria a pouca atenção dada a questões monetárias nos estudos que tratam desse período, principalmente àqueles correspondentes aos dois primeiros séculos de nossa colonização. Considera-se que uma economia escravista, voltada unicamente para a exportação, não teria necessidade de moeda:

$[\mathrm{O}]$ produtor não necessitava de numerário, porque o pagamento do trabalho se reduzia à manutenção do escravo (...). Os próprios feitores e empregados qualificados recebiam principalmente in natura. (...) A moeda, existindo em pequena quantidade, só se acumulava nas cidades mais importantes e ali mesmo somente nas mãos dos mais ricos; estes, por sua vez, não tendo necessidade de um intermediário de trocas, dada a rarefação da população e a exigüidade de suas necessidades, mais a entesouravam do que a faziam circular. (Vieira, 1985, p. 350)

Descrevendo a situação particular do Rio de Janeiro, Lessa (2000, p. 41) apresenta argumento semelhante:

A prosperidade do capital mercantil não foi síncrona com o aumento da circulação monetária interna à vila. Não houve monetização da vida urbana. 
Os ricos, com abundante escravaria doméstica, autarquizavam sua subsistência e de seu grupo familiar correspondente. (...) Haveria um minúsculo comércio interno e alguns poucos artesãos autônomos. Obviamente, os pobres e livres subsistiam com a produção e extração de alimentos para autoconsumo.

A reduzida circulação monetária poderia ser vista, por outro lado, como um entrave ao desenvolvimento da economia colonial, sendo esse também o entendimento das autoridades coloniais. Neste sentido, a moeda seria de fato escassa, uma vez que haveria demanda por moeda não suficientemente atendida pela oferta. Para Wehling (1999, p. 204),

[a] função bancária assumida pelas Santas Casas de Misericórdia, bem como a pura e simples falta de moeda de ouro e prata (...) foram sintomas de um quadro negativo, que impedia o crescimento do mercado interno e comprometia as próprias rendas da Coroa.

Referindo-se à situação monetária do Rio de Janeiro no final da década de 1680, Coaracy (1965, p. 216) afirma que

(...) no Brasil quase só corria a moeda antiga e no Rio de Janeiro essa mesma era escassa e insuficiente para as necessidades do comércio (...)

Aguiar (1972, p. 81-85) descreve as conseqüências da penúria de moeda vivida na Bahia durante o século XVII. As constantes queixas sobre falta de moeda, externadas pela Câmara baiana a partir da década de 1630, e, principalmente, os pedidos de cunhagem de moeda provincial testemunhariam essa escassez. A se acreditar nos documentos da época, a falta de moeda, juntamente com a crescente deterioração da qualidade do meio circulante, constituíram-se, nas últimas décadas do século XVII, em grave problema cuja solução era indispensável até mesmo para a preservação do Brasil como parte integrante do Império.

\subsection{Os levantamentos da moeda}

Até fins do século XVII, foi insignificante a produção de metais no Brasil. Assim, a oferta de moeda metálica dependia fundamentalmente dos fluxos de metais resultantes das relações comerciais com a América espanhola e com Portugal. Na segunda metade daquele século, o influxo de metais foi negativamente afetado pela interrupção do comércio regular com Potosi, 
até então a mais importante fonte de metais amoedados, e pela contínua queda dos preços dos produtos de exportação brasileiros nos mercados europeus (Godinho, 1983). A redução da diferença entre os preços pagos pelo açúcar e pelo tabaco no Brasil e em Portugal teria levado os comerciantes portugueses a preferirem vender aqui seus produtos em troca de moeda, e deixar de comprar os produtos da terra, reduzindo dessa forma os riscos de seus negócios. Aprofundavam-se assim os déficits da balança comercial, mesmo porque as importações, muitas delas essenciais, não podiam ser comprimidas além de um certo ponto. Pela via do comércio exterior, a moeda tornava-se, portanto, cada vez mais escassa. ${ }^{6}$

Contudo, tanto para os governantes do reino como para os da colônia, o problema não estaria relacionado a questões comerciais; sua origem encontrava-se nos diferenciais de valores nominais da moeda. O "levantamento" da moeda - ou seja, o aumento do seu valor extrínseco sem o correspondente aumento do seu valor intrínseco - era visto como solução para o problema da fuga de moeda e, ao mesmo tempo, como fonte de atração de metais do exterior. Em 1642, Portugal, carente de recursos para financiar a Guerra da Restauração, havia retomado essa política, interrompida durante o período da União Ibérica.

Esses levantamentos implicavam a necessidade de recunhagem das moedas, ou que a elas fosse aplicada uma marca. De uma maneira ou de outra, as espécies tinham de passar pelas Casas da Moeda ou por oficinas monetárias, proporcionando ganhos de senhoriagem para a Fazenda Real. Por outro lado, esperava-se que a elevação do valor de face das moedas reduzisse a quantidade de metal pago pelas importações e que se registrasse um aumento da receita das exportações, além de estimular o desentesouramento. A prática, entretanto, mostrou que o problema da fuga de metais não poderia ser resolvido simplesmente através de "guerras monetárias", em que desvalorizações em um país seriam respondidas com desvalorizações em outros. $^{7}$

No Brasil, o agravamento do problema da escassez de moeda metálica levou as Câmaras, com o apoio dos respectivos governadores, a demandar, e às vezes promover, mesmo sem autorização, aumentos do valor nominal das moedas, tanto de ouro como de prata, ${ }^{8}$ com o objetivo de desvalorizar a moeda corrente no Brasil em relação à do reino. Em 1643, o governador da 
Bahia decretou o levantamento de $25 \%$ e $50 \%$, respectivamente, das moedas de ouro e de prata, nestas incluídas as patacas de origem peruana, seguindo sugestão da Municipalidade de Salvador (Mauro, 1988, p. 175). Embora essa medida tenha possivelmente sido adotada defensivamente em reação às desvalorizações da unidade de conta que haviam sido realizadas em Portugal, em 1656 "o Senado da Baía pede mesmo que a moeda real seja mais valorizada no Brasil que em Portugal, para impedir definitivamente a sua fuga da colônia" (Mauro, idem). Aumentos da moeda independentemente do consentimento régio foram realizados também em outras capitanias. Alguns desses levantamentos foram proibidos, como aconteceu em 1682, quando "El-Rei comunica haver indeferido a súplica dos oficiais da Câmara da Bahia para que fosse aumentado o valor da moeda (...)" (Sombra, 1938, p. 95).

Como já mencionado, tais aumentos ajudariam, em tese, a impedir a exportação de moeda, mas não eram capazes de reverter o saldo negativo nas contas externas. Os "levantamentos" encareciam os produtos importados e seus percentuais eram os mesmos em Portugal e nas colônias. Além disso, a elevação do valor nominal da moeda provocava inflação, não apenas de bens de consumo, como também dos insumos necessários à produção. Não obstante, prosseguiram os pedidos de aumentos da moeda. É possível que, crenças à parte, esses pedidos tenham sido motivados pelos interesses de curto prazo dos produtores: solucionando ou não o problema da falta de moeda, as desvalorizações eram benéficas para os setores endividados, nos quais os produtores se incluíam.

Como explica Schwartz (1998, p. 170), a concorrência antilhana impossibilitava que senhores de engenho e lavradores influenciassem o preço do açúcar através do controle da oferta do produto. Logo, concentravam suas demandas em objetivos imediatos: redução dos impostos, aumento do número de navios no transporte de açúcar (para baixar o preço dos fretes), maior oferta de mão-de-obra africana (para baixar o preço) e disponibilidade de crédito a juros reduzidos. Muito provavelmente as queixas sobre a falta de moeda, pelo menos em parte, se encaixariam nesse padrão de conduta, já que, sendo a moeda escassa,

muitas transações foram realizadas através de várias formas de crédito. Como os comerciantes cobravam um ágio por essas operações, os senhores de 
engenho consideravam a falta de moeda uma razão fundamental para seu endividamento e procuravam continuamente modos de alterar as condições que a causavam. (Schwartz, idem $)^{9}$

Por outro lado, aos comerciantes não interessariam os levantamentos da moeda. Em primeiro lugar, porque eram predominantemente credores; e, em segundo lugar, porque a dificuldade de exportar açúcar poderia ser atribuída, pelo menos em parte, às desvalorizações. Como estas tendiam naturalmente a aumentar os custos de produção, a economia açucareira corria o risco de até mesmo se inviabilizar caso os produtores não fossem capazes de repassar essa elevação de custos para o preço do açúcar vendido aos comerciantes sediados no Brasil. Estes, por sua vez, se veriam forçados a vender esse açúcar com menor margem, ou mesmo prejuízo, aos negociantes sediados na colônia, ou em Portugal, por consignação. A contínua queda do preço internacional do produto verificada na segunda metade do século XVII tornava cada vez mais remota a possibilidade de lucro. Com isso, o açúcar acumulava-se nos trapiches, o que contribuía para reduzir ainda mais o seu preço.

\subsection{Falsificação e cerceio de moeda}

Durante o século XVII, boa parte das espécies em circulação era composta por moedas falsas ou cerceadas. A falsificação e o cerceio de moedas eram praticados em toda a Europa, ${ }^{10}$ e no Brasil não poderia ser diferente. Moedas eram cunhadas clandestinamente na colônia, mas possivelmente a grande maioria das moedas falsas que circulavam tinha outra procedência, destacando-se, a partir de meados daquele século, as cunhadas no Peru. Para os colonos, representava um meio de superar a escassez de moeda, verdadeira ou falsa, apesar do risco de punição, que ia da perda da moeda ao degredo. ${ }^{11}$ No entanto, a Coroa evidentemente preocupava-se com a circulação de moedas falsas, porque, desde sempre, a cunhagem de moeda era uma prerrogativa do soberano, que assim monopolizava os ganhos de senhoriagem.

Juntamente com a falsificação, a prática do cerceamento de moedas, geralmente realizado por ourives, constituía-se em uma das principais razões que faziam com que o meio circulante fosse composto por moedas cujos valores nominal e intrínseco diferiam. ${ }^{12}$ Nesse caso, prevalecia a Lei de 
Gresham: a moeda de menor valor intrínseco (a moeda má) expulsava de circulação a moeda boa, já que ambas corriam pelo mesmo valor nominal. ${ }^{13}$ A circulação de moeda cerceada, por sua vez, estimulava a importação de moeda falsa e o entesouramento de moedas "boas", numa espécie de círculo vicioso, pois aumentava a proporção de moeda de "má qualidade" no total do estoque de moeda em circulação.

A partir do início da década de 1680, o governo português procurou coibir o cerceio mais vigorosamente. Pelo Alvará de 17 de outubro 1685,

é proibida a circulação de qualquer moeda da nova fábrica que estivesse cerceada, devendo seus possuidores manifestá-la para receber o seu valor intrínseco, sob novas penas acrescidas às previstas na Ordenação do Reino para os crimes de cerceio e de moeda falsa. (Sombra, 1938, p. 96)

Nos três anos seguintes, novas leis sobre a mesma matéria foram promulgadas. Essa seqüência de leis mostra que as mesmas não vinham sendo devidamente cumpridas em Portugal; no Brasil, teriam sido simplesmente ignoradas. De qualquer modo, retrata ainda a situação de "penúria de numerário" vivida tanto na colônia como na metrópole, onde a moeda também era pouca e de má qualidade (Souza, 2001).

\section{O LeVANTAMENTO DE 1688, AS PATACAS A PESO E OS MOTINS DA MOEDA}

A lei de 4 de agosto de 1688 agravou profundamente o problema da escassez de meio circulante, ao provocar uma forte redução do total do estoque de numerário em termos nominais. A lei determinava o levantamento de $20 \%$ das moedas de ouro e de prata e, mais uma vez, que as patacas passassem a correr a peso. Dessa maneira pretendia-se sanear a circulação monetária ao impor um valor único, em reais, para cada um dos diferentes metais, permitindo que a moeda portuguesa cumprisse plenamente sua função de meio de pagamento.

A idéia por trás do levantamento de $20 \%$ estava de acordo com o pensamento econômico português da época: ajudar a reter a moeda no Reino e atrair metais para a Casa da Moeda de Lisboa. Segundo Sombra (1940, p. 40), essa medida fazia sentido para Portugal, pelo menos no curto prazo, mas, 
[p] ara o Brasil, (...) onde a moeda já era aumentada com consentimento e sem consentimento, representava ele, na verdade, uma baixa em relação ao valor corrente no Reino. E essa baixa tinha uma conseqüência fatal, temida pelos colonos: a evasão do numerário.

Entretanto, além do problema da fuga de moeda, havia outro, mais grave: os detentores de moeda da colônia empobreciam, em virtude da queda do valor de face de suas moedas.

O empobrecimento seria ainda mais sentido no tocante à determinação de que as patacas passassem a correr a peso. Para os colonos, os efeitos dessa medida régia eram mais desastrosos do que os do levantamento, por duas razões: em primeiro lugar, porque a maior parte das patacas então em circulação, como mencionado na seção anterior, tinham um peso "muito aviltado", o que significa dizer que tinham valores nominais superiores — por vezes muito superiores - ao seu valor intrínseco; e, em segundo lugar, porque as patacas eram "o que ali quase exclusivamente corria" (Azevedo, 1929, p. 330). A perda potencial era, portanto, considerável, não só para os indivíduos, mas também para a economia em geral, por implicar a redução nominal do meio circulante.

A elite colonial possivelmente já estava alertada para a possibilidade de endurecimento da posição da metrópole sobre a circulação de "moedas fracas", e já havia se pronunciado sobre a questão de a moeda ter de "correr a peso" antes mesmo da edição da lei de 1688. Em carta de 2 de janeiro do ano anterior, El Rei ordenara ao "Governador Capitão do Rio de Janeiro João Furtado de Mendonça buscasse algum remédio ao dano que na dita Capitania podia resultar correrem nela moedas cerceadas $(. . .)^{\text {"14 }}$

Em setembro de 1687, o Conselho Ultramarino relatava que, no dia 5 de junho daquele ano, o governador respondeu que

comunicando este negócio com os Prelados, Oficiais da Câmara e pessoas principais daquela cidade (...), uniformemente assentaram todos, depois de passados alguns dias que lhes dera para considerarem nele, que toda alteração que houvesse na moeda seria em grande prejuízo daquela Capitania, por não estarem em estado de terem os moradores dela, a considerável perda, que precisamente havia de resultar se a quisessem reduzir ao seu intrínseco valor, e que como o dinheiro que hoje havia naquela conquista, sendo cerceado, não podia passar para este Reino, porque nele se não havia de aceitar conforme a ordem de Vossa Majestade sem que tivesse seu peso declarado 
nela, nem podia passar-se a outra parte por esta mesma razão; e por valerem naquela terra as patacas dois vinténs mais do que neste Reino, com que nesta forma não era possível que saísse daquela capitania...

A mensagem era clara: os habitantes da "conquista" sairiam perdendo com a redução da moeda ao seu "intrínseco valor" e, além disso, o fato de as patacas, mesmo as cerceadas, valerem nominalmente mais do que em Lisboa representava uma forma de evitar sua exportação. O governador do Rio de Janeiro sugeria que

o dinheiro ficasse na mesma forma em que estava, valendo o que tivesse cerceado o mesmo que valia antes de o ser, e desta mesma resolução dera conta ao Governador da Bahia (...)

A promulgação da lei de 4 de agosto de 1688 suscitou os chamados "motins da moeda", ocorridos nas diversas capitanias. Seus governadores viram-se então pressionados, por um lado, pela resistência das Câmaras e, por outro, pela firme disposição da Coroa que, contrariando práticas anteriores, exigia dessa feita o cumprimento estrito de suas determinações.

Na Bahia, tão logo recebeu a notícia, o governador convocou a Câmara, a pedido desta, "resolvendo-se que as moedas que não haviam sido marcadas corressem as de 3 vinténs por 4 , as de 4 por 5 , as de 5 por 6 , as de 6 por 8 (...); o que sendo decidido foi posto em execução sem esperar-se pela aprovação régia" (Azevedo, 1877, v. II, p. 245). Seria, portanto, um levantamento aparentemente um tanto esdrúxulo, porque o percentual do levantamento variava, de acordo com a espécie de moeda, entre $20 \%$ e $33 \%$, fazendo com que modificasse, mais uma vez de forma aleatória, a relação existente entre os valores intrínsecos e extrínsecos das diferentes espécies. Alertado pelo chanceler da Relação, o rei vetou essa resolução que dava "maior e diferente valor à moeda além do declarado na lei" (Azevedo, idem). O disposto na lei de 4 de agosto de 1688 acabou prevalecendo e as patacas foram eventualmente reduzidas.

Fatos semelhantes aos ocorridos na Bahia verificaram-se também no Rio de Janeiro, onde

[r] euniu-se o senado da câmara com o governador e pessoas entendidas nos negócios, e representou a el-rei fosse servido levantar o valor de toda a moeda vinte por cento, que as duas patacas serrilhadas passassem a ter o valor de 
2 cruzados e uma pataca serrilhada a de 1 cruzado. ${ }^{15}$ Tendo o povo notícia dessa deliberação pediu ao governador mandasse executá-la imediatamente, e este, assustado com o motim popular, anuiu ao pedido, porém participando ao rei; em 24 de junho de 1690, seu procedimento foi julgado ilegal e nulo por carta régia de 18 de outubro do mesmo ano. (Azevedo, 1877, p. 246)

Não se sabe ao certo se a proibição surtiu efeito. Em abril e maio de 1691 os oficiais da Câmara enviaram representações ao rei contra a execução da lei de 4 de agosto de 1688, das quais o Conselho Ultramarino tomou conhecimento em novembro daquele ano. ${ }^{16}$ Em 10 de junho de 1694 o governador Antonio Paes de Sande escrevia a El-Rei informando que havia decretado um aumento da moeda. Em 6 de outubro do mesmo ano, o Conde Andrade Sepulveda Serrão, em nome do Conselho Ultramarino, sugere "para que Vossa Majestade mande ver este negócio (...) porque (...) de alguma maneira pareceu ao Conselho se deve emendar por não convir que haja diferença de moeda no mesmo estado do Brasil". ${ }^{17}$

São Paulo constituiu-se em um caso à parte, porque a recusa em obedecer à lei foi ainda mais forte e prolongada: "O problema de numerário fixaria, na história, o grau de independência e rebeldia das capitanias paulistas, que chegariam a decretar a sua própria política monetária!” (Simonsen, op. cit., p. 342). São Paulo decretou, em 1690, um levantamento da moeda de cerca de $20 \%$ a $30 \%$ e, apesar de a medida ter sido considerada, como nos outros casos, ilegal, a Câmara paulista promoveu outra desvalorização da moeda em 1693, dessa vez apenas para as espécies de menor valor — o "dinheiro miúdo" - , perfazendo um aumento do seu valor nominal de 40\% para as moedas de 200 réis e de 100\% para as de 2 vinténs (ou 40 réis).

A independência da política monetária de São Paulo teria chegado a ponto de proteger, via desvalorização, seu meio circulante não apenas das inevitáveis perdas com o comércio exterior, como também prevenir possíveis perdas relacionadas a transações efetuadas com outras partes da própria capitania. Já em dezembro de 1692, portanto antes mesmo do segundo levantamento realizado pelos paulistas no ano seguinte, o governador-geral Câmara Coutinho via nessa postura uma forma de roubo "porque se neste Estado [do Brasil] corre toda a tostão a oitava, ${ }^{18}$ e lá [em São Paulo] a tomam por preço exorbitante, é certo que quem o aceita fica enganado; porque se o quiser tirar da terra, por força o há de baixar, e perder nele" (citado 
em Sombra, 1940, p. 41). Era uma análise correta, apesar de um tanto ingênua, pois a intenção dos paulistas era exatamente essa: através da desvalorização, reduzir a saída de moeda. $\mathrm{O}$ tom das cartas subseqüentes do governador-geral à Câmara de São Paulo tornou-se cada vez mais ameaçador, mas a pressão não surtiu resultado: "[A] Câmara tenta obedecer, mas o povo amotina-se, ameaça, e ela capitula, comunicando, a 30 de janeiro de 1694, a [o novo governador-geral] D. João de Lancastre a impossibilidade de baixar a moeda" (Sombra, idem). A pendenga continuava ainda em janeiro de 1697, quando "o povo de São Paulo amotina-se para obrigar a Câmara a levantar a moeda" (Sombra, 1938, p. 107).

\section{DIAGNÓSTICO E PROPOSTAS DO GOVERNADOR-GERAL EM 1692}

Portanto, nos últimos anos da década de 1680 e nos primeiros da década seguinte avolumaram-se as queixas e os ressentimentos em relação à lei de 1688 e em particular às tentativas de se impor a moeda a peso. Era preciso encontrar uma saída, e as fórmulas apresentadas pelos representantes dos residentes da colônia conformavam-se aos padrões da época. Em 4 de julho de 1692, o governador-geral Câmara Coutinho enviava ao rei uma representação, ${ }^{19}$ expondo suas razões para a falta de numerário e a necessidade de se cunhar moeda provincial. O principal mote de suas demandas eram os prejuízos que a falta de moeda causava ao erário régio. Câmara Coutinho começa citando três razões que, no seu entender, explicariam a escassez de moeda. A primeira delas refere-se às conseqüências sobre o estoque nominal de moedas decorrentes da remarcação dos selos (ou patacas) a peso, então medido em oitavas. Como essas moedas estavam muito gastas, a remarcação teria diminuído fortemente o valor nominal do meio circulante. De acordo com Câmara Coutinho, apenas na cidade de Salvador a perda teria sido superior a 900 mil cruzados. Se seu testemunho é para ser levado em conta, circulavam anteriormente moedas cujo valor nominal chegava a alcançar 800 réis por oitava de prata, mas que a partir de sua "redução a peso" passaram a valer apenas 100 réis a oitava.

O segundo motivo para a escassez de moeda estaria ligado às condições do comércio exterior. Os negociantes portugueses que aqui vinham vender suas mercadorias não se interessavam em comprar açúcar e exigiam pagamento em moeda metálica, já que a diferença entre o preço do açúcar no 
Brasil e em Portugal seria insuficiente para compensar os riscos do negócio, uma situação que já perdurava por décadas. E o terceiro motivo que explicaria a falta de numerário eram as remessas de lucros e outros tipos de transferências.

A seguir, o governador passa a enumerar as conseqüências da lei. Em primeiro lugar, a escassez de moeda estaria provocando a queda do preço do açúcar e dos outros produtos da terra, ao mesmo tempo em que aumentavam os custos de produção por causa do encarecimento das importações provocado pelo aumento da moeda. Se, antes do aumento de 1688 , a situação já era ruim, a conjunção, por um lado, de preços internos em queda pela falta de moeda e, por outro lado, de custos subindo em função da desvalorização traria prejuízo certo, com o que a produção de açúcar e de outros produtos estaria sendo inviabilizada.

Câmara Coutinho explica então as conseqüências orçamentárias da crise acima descrita, começando pela queda nas receitas, cuja principal fonte era o comércio exterior: nessa época, os negócios com a exportação de açúcar do Brasil já representavam parcela significativa, e crescente, das receitas da "Real Fazenda". Mas também a arrematação dos dízimos estava sendo comprometida, tanto pela falta de moeda como pelas expectativas sombrias em relação ao futuro da economia açucareira. Além disso, tornava-se difícil a cobrança de certos tipos de impostos e contribuições, assim como os pagamentos da administração pública "eclesiástica e secular".

O governador advertia, em resumo, que estava ameaçada a sobrevivência da colônia. Sugere então uma solução que considerava simples para a falta da moeda: a cunhagem de 2 milhões de cruzados de moeda provincial, para circular exclusivamente no Brasil. Essas moedas seriam de ouro e de prata e distribuídas entre as principais regiões. Seu valor nominal, de acordo com a proposta, deveria ser superior ao do reino, canalizando-se parte do aumento para a Fazenda Real.

Pela proposta de governador, o valor extrínseco da moeda provincial seria elevado em "20 por 100, a saber 15 para o dono dele e 5 para o dispêndio da fábrica, ficando as sobras para a Real fazenda”. A idéia era cunhar os 2 milhões de cruzados e então fechar a "fábrica", sendo que toda moeda que entrasse no Brasil após o fechamento teria valor nominal idêntico ao de Portugal. 
Em sua carta, Câmara Coutinho refere-se também à situação dos pobres, igualmente carentes de moeda, não de ouro ou prata, mas de cobre. A escassez de moeda de baixo valor nominal dificultava a venda de produtos baratos e o recebimento de esmolas. Pedia por isso a cunhagem de moedas de cobre no valor de 40 mil cruzados.

A resposta inicial do rei, datada de 23 de fevereiro de 1693, não foi favorável. Considerou que as sugestões trariam mais danos do que benefícios para a colônia e também para a metrópole. Como forma de compensação, enviou, através da Junta do Comércio, moedas de baixo valor para serem trocadas por moedas cerceadas. Mas como essas trocas implicavam perda de um cruzado por cada marco de peso, ninguém se interessou. O governador alegaria, em carta enviada em 22 de julho daquele ano, ${ }^{20}$ que não havia moeda cerceada disponível para troca. Na mesma carta, Câmara Coutinho aparentemente parte para a barganha: procura tornar mais atraente sua proposta de criação de uma moeda provincial, modificando-a no tocante às moedas de ouro, que não mais deveriam ser cunhadas por valor $20 \%$ superior ao que corriam em Portugal, mas por um valor igual. Justificando essa mudança em relação à proposta original, o governador mostra-se sensível também aos problemas monetários da metrópole:

Porque como o ouro é coisa que entra neste Estado todos os anos da Costa da Mina cinqüenta e sessenta mil cruzados, não parecia razão que fazendose dele moeda Provincial fique toda neste sem ter conta de passar a esse Reino (...); porque desta sorte servirá destas partes, enquanto não a levarem, $\mathrm{e}$ depois passará ao Reino e desta maneira não ficará desta banda todo o ouro empatado, sem fazer conta para poder passar a esse Reino que também necessita ter muita moeda.

\section{A CRIAÇÃo de UMA CASA dA MOEDA E A CUNHAGEM DE MOEDA PROVINCIAL}

\subsection{A Casa da Moeda da Bahia}

$\mathrm{Na}$ opinião de inúmeros autores, ${ }^{21}$ os argumentos de Câmara Coutinho, apoiados por extensa correspondência enviada por governadores de capitanias e oficiais das Câmaras, parecem ter sido decisivos para que fosse finalmente tomada a decisão de se criar uma Casa da Moeda em Salvador, atra- 
vés de lei publicada em 24 de maio de 1694, cujo preâmbulo repete a tese segundo a qual a queda na arrecadação se devia à falta de moeda. Em seus aspectos gerais, as medidas concretas decididas pelo rei nada diferem daquelas avançadas pelo governador. Quanto aos detalhes, entretanto, havia diferenças. A lei rezava que "o ouro e a prata em todo o estado do Brasil se levantasse dez por cento sobre o levantamento dos vinte por cento que teve neste Reino”, um levantamento inferior ao sugerido por Câmara Coutinho, no caso da prata, e superior, no caso do ouro. Também foi recusado o direito à senhoriagem "porque o meu ânimo é favorecer em tudo os moradores desse Estado como eles merecem pelo amor e lealdade com que sempre me serviram (...)"22 Entretanto, quanto à solicitação de emissão de moeda de cobre, utilizada nas pequenas transações e nas esmolas, nem uma palavra. ${ }^{23}$ Outra diferença é que não foi estabelecido um limite quanto ao valor a ser cunhado, embora talvez não estivesse afastada a possibilidade de fechar a Casa da Moeda após se considerarem concluídos os trabalhos de recunhagem.

Na prática, o percentual do levantamento e a questão da senhoriagem não seguiram nem a proposta de Câmara Coutinho ${ }^{24}$ nem o que previa a lei. A Casa da Moeda da Bahia levantou a moeda em cerca de $17 \%,{ }^{25}$ mas quem entregava recebia só $10 \%$. A diferença foi utilizada para cobrir os custos de instalação e os gastos correntes da Casa da Moeda.

Até ser fechado em 1698, aquele estabelecimento cunhou um total de 921 mil contos de réis - equivalentes a cerca de 2,3 milhões de cruzados —, superando, portanto, o que previa Câmara Coutinho. Desse total, 102 mil contos foram cunhados em moedas ouro e 819 mil contos em moedas de prata (Sombra, 1940, p. 47). Supondo-se, como afirmavam as autoridades locais, que só circulavam espécies de prata, é bem provável que tenha ocorrido desentesouramento tanto de ouro como de prata. No caso específico desta, houve ainda remessas ilegais de patacas de Portugal para a Bahia, pois em carta dirigida ao governador-geral a 12 de janeiro de 1698, o monarca reconhece que "a experiência tem mostrado que com o maior valor que a prata e o ouro têm nesse Estado [do Brasil], se levam muitas patacas desse Reino, sem embargo da proibição em contrário". ${ }^{26}$ Na mesma carta, o rei ordena o fechamento da Casa da Moeda da Bahia, considerando que "o que se tinha lavrado em prata e ouro, cuja importância não só basta, mas sobra, para o uso e comércio dos moradores dessa Capitania (...)” 


\subsection{As idas e vindas da Casa da Moeda}

Em março de 1698, El-Rei informa ao superintendente da Casa da Moeda que esta seria fechada no prazo de um ano após a chegada da frota, por considerar que na Bahia o processo de recunhagem encontrava-se em estado avançado, mas que faltava ainda reduzir as moedas que deveriam ser remetidas das capitanias de Pernambuco, Paraíba e Rio de Janeiro. Quanto à atitude dos pernambucanos, que até então se recusavam a remeter moeda para Salvador, o rei dizia que eles cometiam "o engano de esperarem que se lhe[s] mandassem casa da moeda naquela Capitania" e que ordenara o envio de "todo o dinheiro que tivesse pelo modo que lhe fosse mais suave e afetivo, para que com menos incômodo e prejuízo dos povos se remetesse e reduzisse". Os governadores de Pernambuco e da Paraíba deveriam "deitar Pregões" anunciando que após aquele prazo de um ano "a moeda de Pernambuco que não fosse a reduzir ficaria proibida pois por culpa de seus moradores e pela sua contumácia ficara por reduzir". ${ }^{27}$

De fato os pernambucanos protelaram a remessa de dinheiro, na expectativa de que a Casa da Moeda viesse a ser eventualmente para lá transferida, como de fato acabou acontecendo. A troca de correspondência entre as autoridades sediadas em Salvador e o governador de Pernambuco demonstra as dificuldades da remessa de moeda metálica e os tipos de preparativos necessários para fazê-lo. Os "riscos do mar" seriam suficientemente elevados para justificar o envio de moeda por via terrestre, mas obviamente nem mesmo essa rota era isenta de riscos.

Em carta de março de 1697, em que mais uma vez exigia a remessa da moeda de Pernambuco, o rei, reconhecendo que o Rio de Janeiro era um caso à parte, informava haver escrito para o governador e a Câmara daquela capitania oferecendo-lhes a opção de lá instalarem a Casa da Moeda, após seu fechamento na Bahia, desde que arcassem com as despesas da transferência. Não surpreendentemente,

[a] ceitou o senado da câmara a casa da moeda e agradeceu ao rei este benefício. Em 10 de janeiro de 1698 comunicou-lhe o soberano que ordenara ao governador-geral transferisse para o Rio de Janeiro a casa da moeda, por desejar livrar os moradores desta capitania da opressão que padeciam com a moeda cerceada, deixando em benefício do povo a senhoriagem. (Azevedo, 1877 , v. II, p. 248) 
Em 10 de janeiro de 1698, o rei, mudando de idéia, informou sua decisão de transferir a Casa da Moeda para Pernambuco, desistindo assim de convencer os pernambucanos de enviar moeda para Salvador. A transferência se daria após o encerramento das atividades no Rio de Janeiro, previstas para durar um ano. Vale lembrar que, nesse ínterim, os paulistas ainda lutavam por uma política autônoma de desvalorização.

Nessa primeira vez que funcionou na cidade do Rio de Janeiro, a Casa da Moeda cunhou, entre março de 1699 e outubro do ano seguinte, moedas no valor total de 868,3 mil contos, sendo que, em termos nominais, cerca de $70 \%$ foram de ouro (Gonçalves, 1985, p. 73). Por sua vez, a Casa da Moeda de Pernambuco, cujos trabalhos foram iniciados em outubro de 1701 e duraram exatamente 12 meses, cunhou, ao todo, moedas no valor aproximado de 436 mil contos de réis, $98 \%$ dos quais em moedas de prata (Gonçalves, idem, p. 78). Note-se que muito mais prata foi cunhada em Pernambuco do que no Rio de Janeiro. A explicação pode estar na fuga deste metal para São Paulo, onde o ouro valeria relativamente menos. ${ }^{28}$

A escala em Pernambuco foi a última da Casa da Moeda itinerante. Em 1702 ela voltou para o Rio de Janeiro, mais próxima, portanto, da região aurífera das Minas Gerais.

\section{CONSIDERAÇÕES FINAIS}

Simonsen (1937, v. 1, p. 340) aponta razões fiscais para convencer os governantes portugueses a criar na colônia uma Casa da Moeda:

[a]gravando-se a crise, com a circunstância de baixarem as propostas para os arrendamentos dos dízimos do Brasil, a Coroa portuguesa, pela lei de 8 de março de 1694, fundou a Casa da Moeda da Bahia, reconhecendo o princípio da necessidade de uma moeda provincial.

A crise a que se refere o autor é a da escassez de moeda. Entretanto, devese lembrar que, concomitantemente, ocorria uma crise mais abrangente, a de uma economia cujo dinamismo dependia da exportação de açúcar e de outros poucos produtos de exportação. A percepção geral era de que as duas crises estavam vinculadas, que uma alimentava a outra. A dificuldade de exportar reduzia o estoque de moeda, que por sua vez dificultava as importações necessárias para manter não apenas a produção de açúcar, mas tam- 
bém a de outros produtos. Conseqüentemente, a queda da arrecadação dos dízimos não era devida somente à falta de moeda, mas refletia também a deterioração das expectativas quanto à situação econômica em geral. Se obviamente não era possível intervir no mercado internacional de açúcar por decreto, restava minorar o problema da falta de numerário com a criação de uma moeda provincial.

Uma das maiores queixas dos colonos, expressa em farta correspondência enviada à metrópole, era a de que os importadores preferiam levar moeda a comprar açúcar e outros produtos da terra, fato que, além de provocar a redução do meio circulante, deprimia o preço das mercadorias exportáveis. Caso circulasse exclusivamente moeda provincial, cuja exportação era proibida, os importadores talvez se vissem compelidos a comprar o açúcar como pagamento pelos produtos aqui vendidos, já que estes não poderiam ser pagos em moeda pelos colonos. A situação agora se reverteria: a obrigatoriedade de levar açúcar - ou outros produtos da terra — poderia ajudar a sustentar ou mesmo elevar seus preços.

É possível ainda considerar a hipótese de que as propostas de criação de uma moeda provincial, e não apenas de um simples levantamento da moeda, provavelmente não visassem atender apenas aos interesses da Fazenda Real ou dos senhores de engenho. Se as mercadorias importadas eram pagas em moeda corrente e as frotas não embarcavam açúcar, os grandes comerciantes não tinham como converter, em moeda, o que lhes pagavam, em açúcar, os senhores de engenho. Naquele momento, portanto, o açúcar era uma moeda inconversível. Pior, perecível. A impossibilidade de comercializar as safras fazia os homens de negócios — talvez apenas temporariamente, talvez não - perder a sua lucrativa função de intermediários na cadeia de crédito, sem contar o problema do já elevado nível vigente de inadimplência. Estariam talvez conscientes do fato de que enquanto não se elevassem as exportações de açúcar, não se resolveria a questão da virtual insolvência dos seus mutuários. Mas o aumento da circulação monetária - assim como a expectativa de sua estabilização, que seria conseguida com a proibição da exportação da moeda provincial - serviria para minorar, pelo menos no curto prazo, o problema da falta de liquidez.

O arrefecimento dos "motins da moeda" e do ressentimento dos colonos pelas perdas sofridas com a lei de 4 de agosto de 1688 coincidiu com os 
avanços dos trabalhos da Casa da Moeda ambulante. Mas, como afirma Levy (1983), a curta duração dessa experiência não permite uma avaliação de seus impactos.

De qualquer forma, vale enfatizar que os acontecimentos relatados neste trabalho sugerem que o fato de a moeda ter sido escassa no período colonial não significa que questões monetárias não fizessem parte das preocupações dos colonos e das autoridades locais: os colonos se queixavam da "falta de numerário" porque havia demanda por moeda metálica, enquanto que os representantes do reino acreditavam que a escassez de moeda impunha limites ao desenvolvimento dos negócios e, portanto, à arrecadação de impostos. Neste sentido, a criação de uma Casa da Moeda na colônia para a cunhagem de moeda provincial era vista como uma forma de contornar um problema considerado vital por muitos contemporâneos.

Ao mesmo tempo em que se desenvolviam as atividades da Casa da Moeda "itinerante", dois fatos contribuiriam para minorar o problema monetário, tanto na colônia como na metrópole, na passagem do século XVII para o XVIII: por um lado, a recuperação econômica européia, que possibilitou a elevação do preço das mercadorias exportáveis; por outro lado, e talvez mais importante, começavam a ser sentidos os efeitos da exploração das recém-descobertas minas de ouro, ${ }^{29}$ como indicam os totais cunhados pela Casa da Moeda do Rio de Janeiro em 1699 e 1700. Com as descobertas de ouro "desapareciam os embaraços financeiros da administração; as rendas do Estado cresciam em toda a parte; a falta de espécies monetárias deixou de sentir-se (...)" (Azevedo, 1929, p. 330). Para Portugal, não fazia mais sentido que, com tanto ouro a ser enviado à Casa da Moeda, as moedas cunhadas ficassem obrigatoriamente retidas no Brasil. Com isso, a Casa da Moeda, ao retornar para o Rio de Janeiro em 1702, deixou, por quatro décadas, de cunhar moeda provincial, emitindo exclusivamente moeda "nacional", ou seja, iguais às cunhadas pela Casa da Moeda de Lisboa. A moeda provincial, entretanto, continuou a circular no Brasil até o final do período colonial, mantendo seu valor extrínseco $10 \%$ superior à do Reino.

\section{NOTAS}

1. "É importante especificar tanto a incerteza como os custos de transação como condições necessárias para a existência de moeda, já que incerteza envolve custos de transação. De fato, custos de transação refletem principalmente, se não completamente, custos de obter informação i. e., de reduzir incerteza" (Goodhart, 1989, p. 28-29). 
2. Também para a cunhagem de moedas havia uma permanente busca de melhoria técnica, de tal maneira a baratear seu custo de produção, facilitar a sua identificação e dificultar a falsificação. Sobre os avanços técnicos na cunhagem na Europa, ver Sargent e Velde (1997). Para o caso específico de Portugal, ver Bastien (1991).

3. Ver, a respeito, Wray (1998) e Goodhart (1989).

4. O fato de que certas moedas emitidas nacionalmente tiveram circulação internacional pode dar a entender que sua aceitação estava vinculada ao poder do Estado emissor. Entretanto, sua aceitação se dava porque seu valor intrínseco permanecia imutável por longos períodos, o que facilitava seu reconhecimento e, portanto, reduzia os custos de transação. De qualquer forma, muitas vezes, no Oriente, até mesmo essas "moedas de prestígio" eram derretidas e recunhadas por governantes locais, exatamente com o objetivo de facilitar o comércio regional (Godinho, 1991).

5. Em 1800, esse valor foi elevado para 5.000, à época inferior ao de certas moedas de ouro cunhadas no Rio de Janeiro e em Lisboa.

6. Para uma explicação mais detalhada dos fluxos de metais no Brasil nos séculos XVI e XVII, ver Lima (2005).

7. Godinho (1991) e Dias (1998) descrevem algumas dessas "guerras monetárias".

8. A partir daquele ano foram criadas, no Brasil, oficinas monetárias apenas para "recarimbar" moedas. Essas oficinas não tinham condições técnicas de cunhar novas moedas.

9. Pela mesma razão, os comerciantes, na posição de credores, se oporiam aos levantamentos decretados pelas Câmaras. As Ordenações Afonsinas proibiam a chamada "cláusula ouro", isto é, a atualização monetária dos contratos (Jansen, 1991). A desvalorização representava, portanto, uma diminuição da dívida em termos reais, prejudicando os comerciantes e beneficiando os devedores, dentre os quais se destacavam os senhores de engenho, não por acaso favoráveis à medida.

10. Ver, por exemplo, Konh (1999); Souza (1999); Godinho (1991).

11. Por ocasião da remarcação de 1663, o Conde de Óbidos escreveu ao governador de Pernambuco acusando ter recebido deste uma carta "acerca dos cúmplices da moeda" que haviam sido presos naquela capitania por haverem realizado a aplicação de marcas clandestinamente (Barros, 1943, p. 327).

12. Até mesmo as moedas não cerceadas ou falsificadas tinham seus valores nominais muitas vezes inconsistentes com seus valores intrínsecos, situação que perdurou pelo menos até o início do século XIX.

13. A Lei de Gresham só se aplica, como lembram Hayek (1986) e Mundell (1998), quando a taxa de câmbio entre as duas moedas é fixa. Selgin (2003) acrescenta que não basta que haja uma paridade oficial, mas também um Estado capaz de impor sanções a quem não cumpra as paridades estabelecidas. Acreditamos que esse fosse o caso de Portugal naquela época.

14. Instituto Histórico e Geográfico Brasileiro. Conselho Ultramarino. Arquivo 1.1.22, p. 145-146. As citações seguintes foram extraídas do mesmo documento. 
15. Uma pataca serrilhada valia 320 réis. Pretendia-se que fosse elevada a 400 réis, o que corresponderia a um aumento de $25 \%$. Talvez fosse uma forma de "arredondamento", já que um aumento de $20 \%$, conforme determinava a lei, levaria a pataca a valer 384 réis. De qualquer maneira, um arredondamento para cima.

16. Juntamente com representação de conteúdo semelhante enviado pela Câmara de Pernambuco (Sombra, idem).

17. Instituto Histórico e Geográfico Brasileiro. Conselho Ultramarino, arquivo 1.1.22, p. 251.

18. Se o governador-geral não estava blefando, o levantamento de 1688 estaria em vigor, nessa data, em todo o restante do Estado do Brasil, com as moedas valendo, proporcionalmente, 100 réis (um tostão) a oitava (cerca de 3,5 gramas) de prata, ou fração.

19. Citada no original em Gonçalves (1985, p. 54-56). Noya Pinto (1979) apresenta um resumo comentado dessa mesma carta.

20. Biblioteca Nacional, Documentos Históricos, v. 38, p. 151-153.

21. Como, por exemplo, Azevedo (1929), Sombra (1940), Gonçalves (1985) e Noya Pinto (1979).

22. Por ocasião do levantamento de 1688, os moradores da metrópole haviam sido igualmente isentos da senhoriagem, sendo que o rei certamente esperava que os custos com a instalação da Casa da Moeda fossem mais do que compensados com o aumento da arrecadação em geral, e das arrematações, em particular.

23. A moeda de prata de menor valor cunhada pela Casa da Moeda da Bahia foi o vintém (20 réis). Esse valor, embora baixo, não atendia plenamente às necessidades de troco. Sampaio (2003) analisa a circulação de moeda de cobre no Rio de Janeiro na segunda metade do século XVII e na primeira do século seguinte.

24. Que então já não mais ocupava o cargo de governador-geral.

25. A lei de 4 de agosto de 1688 estabeleceu o preço do marco de ouro de 8 onças em $105 \$ 600$. A Casa da Moeda trabalhava com o valor de $112 \$ 640$. No caso da prata de 11 dinheiros, os valores eram respectivamente de 7\$040 e 7\$600 (Gonçalves, 1985).

26. Livro I (folhas $71 \mathrm{~V}$ a $72 \mathrm{~V}$ do Arquivo da Casa da Moeda, citado em Gonçalves (op. cit., p. 64-65).

27. Livro I (folha $70 \mathrm{~V}$ a $71 \mathrm{~V}$ do Arquivo da Casa da Moeda, citado em Gonçalves (op. cit., p. 69).

28. Em carta de 8 de junho de 1700, o governador do Rio de Janeiro, Artur de Sá e Menezes, informava Lisboa sobre o "miserável estado em que se acha aquela cidade e seu recôncavo com a falta de moeda de prata (...) havendo somente a de ouro por a de prata ter ido para São Paulo em razão dos Paulistas a troco dela venderem o ouro mais barato (...)" (IHGB, Arq. 1,1,22, p. 389 v., citado em Sampaio, 2003, p. 10).

29. A descoberta de ouro trouxe uma série de modificações na circulação monetária no Brasil. A Bahia voltou a sofrer com a escassez de moeda metálica já nas primeiras décadas do século XVIII, por razões explicadas em Noya Pinto (1979) e Russel-Wood (1968). 


\section{REFERÊNCIAS BIBLIOGRÁFICAS}

AGUIAR, P. (1972) Encruzilhadas da história. Salvador: Progresso.

AZEVEDO, J. L. (1929) Épocas de Portugal Econômico. Lisboa: Livraria Clássica.

AZEVEDO, M. D. (1877) O Rio de Janeiro, sua história, monumentos, homens notáveis, usos e curiosidades. Rio de Janeiro: B. L. Garnier.

BARROS, A. S. (1943) O regimento do Conde de Óbidos diante da história e da legislação monetária. Rio de Janeiro: Anais do Museu Histórico Nacional, v. IV.

BASTIEN, C. (1991) "Para a história da Casa da Moeda de Lisboa: aspectos técnicos e organizativos da produção de moeda metálica”. Estudos de Economia, v. XII, n. 1.

COARACY, V. (1965) O Rio de Janeiro no século dezessete. Rio de Janeiro: José Olympio.

DIAS, J. J. A. (1998) A moeda. In: J. Serrão e A. H. de Oliveira Marques (ed.), Nova História de Portugal, v. V, Portugal do Renascimento à Crise Dinástica. Lisboa: Editorial Presença.

GODINHO, V. M. (1991) Os descobrimentos e a economia mundial. 2 v. Lisboa: Editorial Presença.

(1983) "Portugal, as frotas do açúcar e as frotas do ouro". Estudos Econômicos, n. 13 (especial), p. 719-732.

GONÇALVES, C. B. Casa da Moeda do Brasil: 290 anos de história, 1694-1984. Rio de Janeiro.

HAYEK, F. A. (1986) Desestatização do dinheiro. Rio de Janeiro: Instituto Liberal.

KOHN, M. (1999) Medieval and Early Modern Coinage and its Problems. Hanover: Department of Economics, Working Paper 99-02.

JANSEN, LE (1991) A face legal do dinheiro. Rio de Janeiro: Renovar.

LESSA, C. (2000) O Rio de todos os Brasis: uma reflexão em busca de auto-estima. Rio de Janeiro: Record.

LEVY, M. B. (1983) “Elementos para o estudo da circulação da moeda na economia colonial”. Estudos Econômicos, n. 13 (especial), p. 825-840.

- (1979) História financeira do Brasil Colonial. Rio de Janeiro: IBMEC.

LIMA, F. C. G. C. (2005) "Uma análise critica da literatura sobre a oferta e a circulação de moeda metálica no Brasil nos séculos XVI e XVII”. Estudos Econômicos, v. 35, n. 1.

MAURO, F. (1988) Portugal, o Brasil e o Atlântico: 1570-1670, v. 2. Lisboa: Editorial Estampa.

MUNDELL, R. (1998) “Uses and abuses of Gresham's Law in the history of money”. Zabreg Journal of Economics n. 2 , p. 3-38. Disponível em http://www. Columbia.edu/ ram15/ grash.html

NOYA PINTO, V. (1979) O ouro brasileiro e o comércio anglo-português: uma contribuição aos estudos da economia atlântica no século XVIII. 2. ed. São Paulo: Companhia Editora Nacional.

RUSSELL-WOOD, JR. (1981) Fidalgos e Filantropos: a Santa Casa da Misericórdia da Bahia, 1550-1755. Brasília: Editora Universidade de Brasília.

SAMPAIO, A. C. J. (2003) Crédito e circulação monetária na colônia: o caso fluminense, 16501750. V Congresso Brasileiro de História Econômica. ABPHE, Caxambu, 7 a 10 de setembro. 
SARGENT, T. J., VELDE, F. (1997) The Evolution of Small Change. Federal Reserve Bank of Chicago, Working Paper Series.

SCHWARTZ, S. B. (1988) Segredos internos: engenhos e escravos na sociedade colonial, 15501835. São Paulo: Companhia das Letras.

SELGIN, G. (2003) “Gresham’s Law. EH.Net Encyclopedia”. Robert Whaples (ed.), June 10. Disponível em URL http://eh.net/encyclopedia/?article=selgin.gresham.law

SIMONSEN, R. (1937) História econômica do Brasil, 1500-1820. São Paulo: Companhia Editora Nacional.

SOMBRA, S. (1940) Pequeno esboço de história monetária do Brasil Colonial. Rio de Janeiro: Imprensa Nacional.

(1938) História monetária do Brasil Colonial. Repertório cronológico com introdução, notas e carta monetária. Edição revista e aumentada. Rio de Janeiro: Laemmert.

SOUZA, R. M. (2001) Moeda e estado: políticas monetárias e determinantes da procura, 16881797. Série Documentos de Trabalho, DT/WP n. 20. ISEG, Universidade Técnica de Lisboa.

(1999) Moeda e metais preciosos no Portugal setecentista, 1688-1797. Tese de Doutorado), Universidade Técnica de Lisboa. Lisboa: ISEG.

VAN DER WEE, H. (1997) “Monetary, credit and banking systems”. In: E. E. Rich e C. H. Wilson, The Cambridge Economic History of Europe, v. V. Cambridge: Cambridge University Press.

VIEIRA, D. T. (1985) “A política financeira”. In: S. B. Holanda (dir.), História geral da civilização brasileira I: A época colonial - 2. Administração, Economia e Sociedade. São Paulo: Difel.

WEHLING, A., WEHLING, M. J. C. M. (1999) Formação do Brasil Colonial. 2. ed. Rio de Janeiro: Nova Fronteira.

WRAY, L. R. (1998) Understanding Modern Money: the key to full employment and price stability. Cheltenham, UK: Edward Elgar. 